J. Amer. Soc. Hort. Sci. 115(2):269-273. 1990.

\title{
Changes in Grape Berry Exudates during Fruit Development and Their Effect on Mycelial Growth of Botrytis cinerea
}

\author{
Merilark Padgett and Janice C. Morrison \\ Department of Viticulture and Enology, University of California, Davis, CA 95616
}

Additional index words. Vitis viniferu, pathogen inhibition

\begin{abstract}
Grape berries (Vitis vinifera L., 'Thompson Seedless') exuded a variety of compounds through the cuticle and epicuticular wax layer onto the berry surface. The composition of the exudate changed through the course of the growing season. Phenolic compounds and malic acid were in relatively high concentrations in grape berry exudates after bloom, but were low in exudates from mature fruit. The rate of decrease of phenols and malic acid was more rapid during the early stage of berry growth than during the ripening period. Sugar and potassium concentrations in the berry exudates were low at bloom, but increased rapidly in the later stages of ripening. Water extracts of berry exudates contained sugars, malic acid, potassium, and sodium. The water extracts promoted mycelial growth of Botrytis cinerea Pers. Ethanol and ether extracts contained phenols and lipids. These fractions from fruit sampled in the first 3 weeks after bloom strongly inhibited mycelial growth. The inhibitory effect of these fractions decreased later in the season.
\end{abstract}

Botrytis cinerea is the primary causal agent of bunch rot in grapes and causes economic damage in vineyards worldwide (Sail et al., 1981). Although inoculum is present throughout the growing season (Coley-Smith et al., 1980), grape berries are relatively resistant to infection during the early developmental stages (Hill et al., 1981); McClellan and Hewitt (1973) suggested that $B$. cinerea can infect the grape pistil at bloom, and that these infections can remain latent in developing fruit until veraison or later. However, other authors were not able to detect latent infections within the berries and suggested that colonized floral debris could be the source of inoculum for later infections (Savage and Sail, 1981). It is not until after the start of ripening that disease development occurs (Hill et al., 1981).

Marois et al. (1986) suggested that the cuticle and wax layer of the grape berry affect fungal growth. Both the thickness and structure of these layers change over the course of the season (Bessis, 1972a; Rosenquist and Morrison, 1988). There have been reports of perforations or microfissures in the cuticle, located most abundantly in the peristomatic areas (Bessis, 1972b; Blaich et al., 1984). Pucheu-Planté and Mercier (1983) suggested that these micro fissures may serve as avenues of entry for $B$. cinerea infections. Exudates visible by scanning electron microscopy are present and associated with a high activity of

Received for publication 28 Feb. 1989. We thank Harry Andris for his assistance and the California Raisin Advisory Board and California Table Grape Commission for their financial support. The cost of publishing this paper was defrayed in part by the payment of page charges. Under postal regulations, this paper therefore must be hereby marked advertisement solely to indicate this fact. microflora in the peristomatic areas during grape maturation (Bessis, 1977).

The presence of stimulator or inhibitory compounds on the berry surface may affect the growth of $B$. cinerea (Doneche, 1986; Kosuge and Hewitt, 1964; Nyerges et al., 1975; Pezet and Pent, 1984). Nutrient compounds are important for conidial germination and subsequent host penetration (Blakeman, 1975; Brown, 1925; Coley-Smith et al., 1980; Harper et al., 1981). Conversely, the presence of anti-fungal compounds on or in the host tissue may inhibit germination and infection (Langcake, 1981; Nyerges, 1975). Grape berries exude onto their surface both inhibitory (Pezet and Pent, 1984) and stimulator compounds (Bessis, 1977; Doneche, 1986; Kosuge and Hewitt, 1964). Grape exudates contain sugars (Kosuge and Hewitt, 1964), organic acids (Doneche, 1986), and amino acids (Padgett, 1989). The ability of the exudates to promote or inhibit Botrytis infection varies over the course of the season (Kosuge and Hewitt, 1964; Pezet and Pent, 1984). Grape berry exudates stimulate the growth of $B$. cinerea during the ripening period, an effect that increases during the month prior to harvest (Doneche, 1986).

The objectives of the work described here were to investigate more fully changes in the composition of grape berry exudates during fruit development and to examine the effects of compounds extracted from the berry surface and epicuticular wax layer at various stages of berry development on the growth of $B$. cinerea mycelia.

\section{Materials and Methods}

A block of 54 vines in a commercial 'Thompson Seedless' vineyard near Fresno, Calif. was chosen for the study. The 
vines received a bloomtime thinning spray of $10 \mathrm{ppm}$ gibberellic acid (Pro-Gib, Abbott Laboratories, North Chicago, Ill.). Standard viticultural practices were used to control powdery mildew and insects. There was no evidence of disease or insect infestation in the vineyard at any time during the growing season.

Cluster samples were taken at 7- to 10-day intervals, for a total of 12 sampling dates spanning the growing season from bloom until harvest. The first five sampling dates were before and the last seven sampling dates were at or after the onset of ripening (veraison). Early in the season, several clusters were sampled from each vine. As the fruit increased in size, one cluster per vine was used for each sample.

Individual berries were removed from the clusters with scissors, taking care to leave the pedicels intact. Damaged berries and those without pedicels were discarded. Volume of representative berries from the same clusters was determined by water displacement and was used to calculate berry surface area, assuming an ovoid berry shape (Padgett, 1989).

For exudate extraction, individual berries were immersed sequentially into vials containing known volumes of solvents of decreasing polarity, taking care to keep the pedicels above the surface of the solvent at all times. The volume of both the vials and solvents was increased through the season to accommodate berry growth. The berries were immersed in distilled water for $1 \mathrm{hr}, 95 \%$ ethanol for $20 \mathrm{~min}$, then diethyl ether for $20 \mathrm{~min}$. The water soluble extracts were lyophilized, the ethanol and ether extracts were evaporated to dryness under a stream of filtered air in a warm water bath. The dried extracts were stored at $-8 \mathrm{C}$. Exudates were extracted from duplicate lots of 100 berries each on each sampling date.

The water-soluble extracts were redissolved in a known volume of distilled water and assayed calorimetrically for sugars (Updegraff, 1969), malic acid (Bergmeyer, 1974), and tartaric acid (Vidal and Blouin, 1978). All calorimetric assays were read on a Milton-Roy Spectronic 1201 spectrophotometer (Rochester, N.Y.). Inorganic cations in the water-soluble extracts were identified and quantitated by emission spectroscopy on a PerkinElmer 2380 Atomic Absorption Spectrophotometer (Norwalk, Corm.). Potassium was read at $766.5 \mathrm{~nm}$ and sodium at 589 $\mathrm{nm}$. The ethanol-soluble extracts were assayed for phenolic compounds using the Folin-Ciocalteau method (Singleton and Rossi, 1965). The presence of phenolic compounds in the ether and ethanol extracts were confirmed by thin layer chromatography (TLC) on silica gel plates using a 40 toluene : 25 chloroform :35 acetone (by volume) mobile phase. The dried plates were developed with aqueous $1 \%$ ferric chloride and $1 \%$ potassium ferricyanide.

Lipids in the ether soluble extracts were analyzed by gas chromatography of methyl esterified fatty acids (Labavitch et al., 1982) on a Perkin-Elmer 8320 Capillary Gas Chromatography, using a DB-225 column (J\&W Scientific, Rancho Cordova, Calif.).

The three extracts of grape berry exudates from each sampling date were tested for the presence of compounds able to promote or inhibit growth of $B$. cinerea mycelia by separating compounds by TLC on silica gel plates. Each duplicate sample was replicated twice. Control channels were also run without grape extracts. The TLC plates spotted with the water and ethanol extracts were run in a mobile phase of 4 butanol : 1 acetic acid $: 5$ water (by volume); those with the ether extracts were run in a 3 chloroform : 1 methanol (v/v) mobile phase. Each chromatogram was stopped when the solvent front had moved 10 $\mathrm{cm}$. The solvents were evaporated from the plates at room temperature.

The source of $B$. cinerea used for the mycelial growth assays and as a reference standard was a culture isolated, identified, and maintained by N.F. Sommer (Pomology Dept., Univ. of California, Davis). For the assay, the B. cinerea was cultured on V-8 juice agar [Campbell's V-8 juice, $1 \%$ glucose (w/v), $2 \%$ agar (w/v), $\mathrm{pH}$ 7.0] for 2 weeks at 22C. Conidia were harvested by swirling the fungal culture in sterile, distilled water containing 1 drop of Tween 80 per $100 \mathrm{ml}$ and a few sterile glass beads to break up the conidial chains. The suspended conidia were filtered through four layers of sterile cheesecloth and washed several times in the dilute Tween 80 solution, centrifuging and decanting between washes. The conidia were suspended in potato dextrose broth [PDB, $8 \mathrm{~g}$ potato extract/liter (Difco, Detroit) and $20 \mathrm{~g}$ glucose/liter in $\mathrm{H}_{2} \mathrm{O}, \mathrm{pH}$ 7.0].

The dried TLC plates were sprayed to wetness with the spore suspension of $B$. cinerea conidia in PDB at $1.8 \times 10^{6}$ spores/ $\mathrm{ml}$. Each plate was incubated at $25 \mathrm{C}$ in a closed plastic box lined with saturated paper towels to maintain high humidity. After 3 days, the plates were examined visually and mycelial growth was rated on a 4-point scale, where $1=$ less than $10 \%$ of the mycelial growth of the control, $2=$ about $10 \%$ to $80 \%$, $3=$ about $80 \%$ to $120 \%$, and $4=$ greater than $120 \%$ of the mycelial growth of the controls.

Berries and flower parts from each of the sampling dates were tested for the presence of $B$. cinerea conidia on their surface by incubating in petri plates on potato dextrose agar (PDA). After 3 to 5 days, the plates were examined under a dissecting microscope and the sporulating structures were identified by comparison to published drawings (Barnett, 1987) and to the $B$. cinerea reference culture.

Data were analyzed by analysis of variance (MSTAT, Michigan State Univ., East Lansing).

\section{Results}

Grape berries were sampled at weekly intervals from bloom on 10 May 1988 through harvest, 107 days later, when the grapes had reached $22 \%$ sugar. The early growth stage lasted 4 weeks, followed by the lag phase from $\approx 29$ days after bloom until veraison (40 days after bloom), which marks the second stage of growth and the start of ripening.

The water extracts of berry exudates contained sugars, malic acid, potassium, and sodium. Although tartaric acid is a major component of the juice of grape berries, tartaric acid was not detected in the berry exudates on any sampling date (data not shown).

The amount of malic acid extractable from the berry surface decreased $(P<0.001)$ over the course of the season (Fig. 1A). Malic acid was highest 1 week after bloom, then decreased rapidly until veraison. Malic acid fluctuated between $10 \%$ and $15 \%$ of the bloomtime value from veraison until harvest.

The amount of sugar in the berry exudates increased $(P<$ 0.001 ) per unit surface area over the course of the season (Fig. $1 \mathrm{~B})$. The most rapid period of increase began $\approx 1$ month after veraison.

The $\mathrm{K}$ content of the berry exudates fluctuated during the early part of the season, then increased $(P<0.001) 1$ month after the start of ripening (Fig. 1C). The amount of $\mathrm{Na}$ on the berry surface was slightly less than that of $\mathrm{K}\left(<1 \mathrm{ng} \cdot \mathrm{cm}^{-2}\right)$. It increased from bloom through veraison, then decreased $(P<$ 0.001 ) with continued berry growth (data not shown).

The ethanol extracts of the fruit exudates contained primarily 

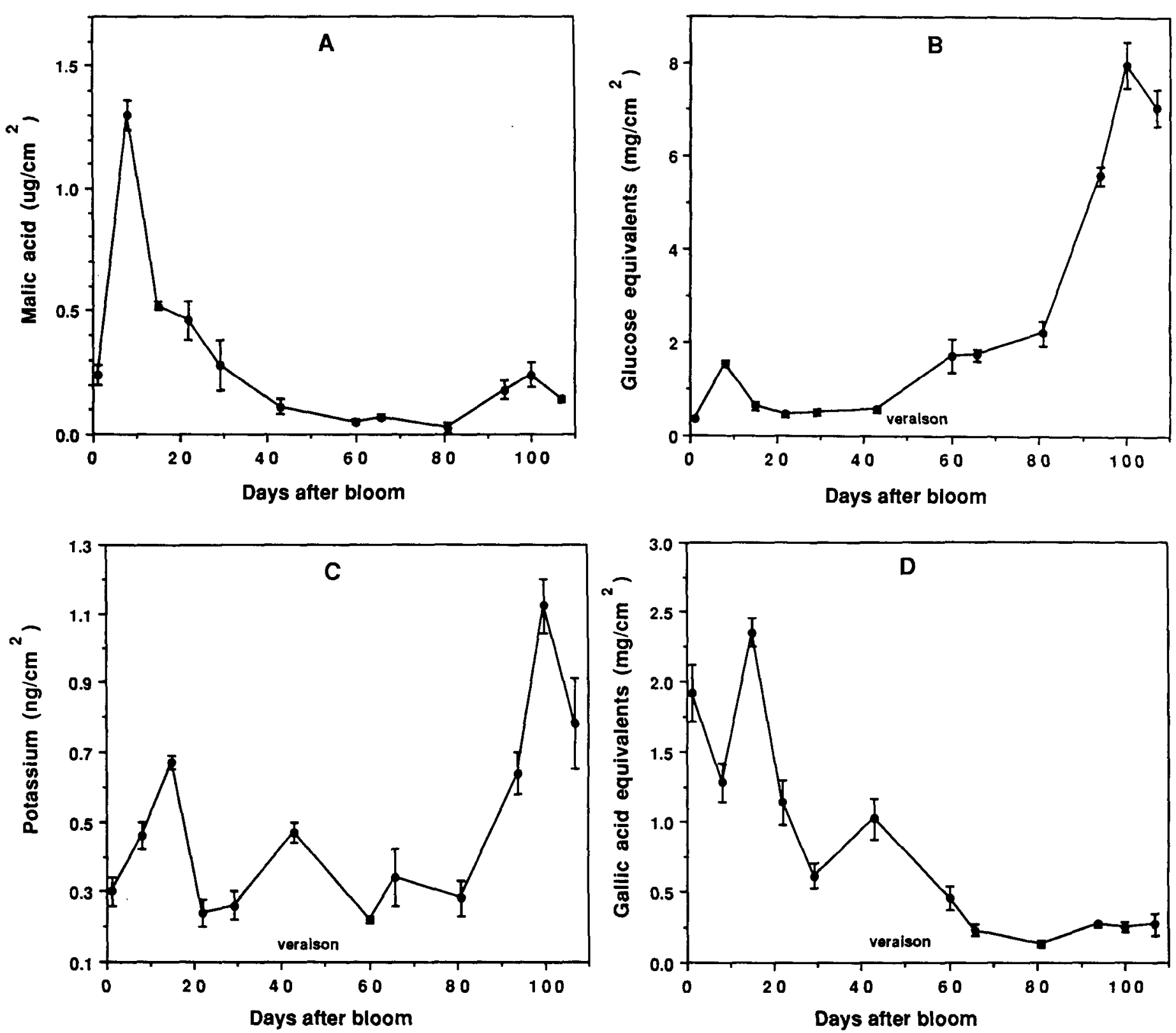

Fig. 1. Changes in the concentration of various exudates on the surface of 'Thompson Seedless' grape berries during the growing season (all per unit of surface area). (A) Malic acid. (B) Sugar as glucose equivalents. (C) Potassium. (D) Phenols as gallic acid equivalents. Standard error bars indicate $P<0.05$.

phenolic compounds. The amount of phenols per unit surface area was highest 2 weeks after bloom, then, except for a transient increase corresponding to the lag phase of berry growth, decreased steadily to $\approx 10 \%$ of the bloomtime amount at harvest $(P<0.001$, Fig. 1D).

The ether extracts contained primarily lipid and phenolic compounds from the epicuticular wax layer. GC analysis of methyl esterified fatty acids showed that about 30 compounds were present in this fraction, but no attempt was made to identify individual compounds.

In mycelial growth assays, substances present in the water extracts of grape berry exudates promoted growth of $B$. cinerea on each of the sampling dates from bloom through commercial harvest. Mycelial growth was rated as 4.0 on all sampling dates, which indicated that growth was consistently $>120 \%$ of that of the PDB controls. Substances present in the ethanol extracts of early season samples with $R f$ values from 0.7 to 1.0 strongly inhibited growth of $B$. cinerea, and mycelial growth on these spots was rated 1.0. Below this zone $(R f$ values $<0.7)$, mycelial growth was similar to the control channels, and was rated 3.0. The inhibition was seen only with extracts from berries sampled from bloom until 3 weeks after bloom (four sampling dates). Ethanol extracts of exudates sampled for the remainder of the season did not inhibit the growth of $B$. cinerea mycelia (rating 3.0). There were also substances present in the ether-soluble extracts that inhibited B. cinerea. The zones of inhibition had $R f$ values from 0.8 to 1.0 in the samples from anthesis, and from 0.9 to 1.0 in later samples. These zones in extracts from anthesis through the 3rd week after anthesis were rated 1.0. These zones in extracts from 1 month after anthesis through the 
start of the ripening period were rated 1.5. The ether extracts of exudates from fruit sampled after veraison did not inhibit mycelial growth (rating 3.0). The control channels had uniform growth, with a rating of 3 on all of the chromatograms, indicating no effect of the chromatography solvents on mycelial growth.

$B$. cinerea conidia were present and viable from bloom through harvest on flower parts and berries that had been cultured on PDA. At each sampling date, all the flower parts tested positive for the presence of $B$. cinerea conidia, and three or more of the 16 berries tested for each date showed $B$. cinerea conidia sporulation within 3 to 5 days.

\section{Discussion}

Many of the compounds that accumulate as storage products within the grape berry were also found to be exuded through the cuticle and epicuticular layer to the surface of the fruit. The composition of the exudate changed significantly over the course of the season. Although changes in some exuded compounds could be correlated to changes in the composition of the berry as a whole, this was not true for all compounds in the exudates.

The decrease in malic acid over the season is in agreement with Doneche (1986), who similarly found organic acids in water extracts of grape exudates, and correlated the drop in exudate acid content after veraison with the decrease in organic acid content in the fruit during ripening. However, data reported here show that the highest amount of malate per unit berry surface area was shortly after bloom, when the concentration of malate inside the fruit is relatively low (Crippen and Morrison, 1986). By veraison, when malate within the fruit normally reaches its highest concentration (Crippen and Morrison, 1986), malate in the exudate had declined to $\approx 10 \%$ to $15 \%$ of its earlier value. The decrease in malic acid may indicate a change in the buffer capacity and $\mathrm{pH}$ of the berry surface over time. Doneche and Pucheu-Planté (1986) found that both germination of B. cinerea conidia and mycelial growth responded to $\mathrm{pH}$. They reported an optimum at $\mathrm{pH} 4.0$, with depressed growth at either higher or lower values, and total inhibition at $\mathrm{pH}$ extremes. The $\mathrm{pH}$ at the berry surface was not measured in this study; however, the 10 -fold decrease in malic acid combined with a large increase in $\mathrm{K}$ per unit surface area suggests a rise in surface $\mathrm{pH}$. If such a change in $\mathrm{pH}$ occurs, it seems likely that it may contribute to the changes in grape berry susceptibility to $B$. cinerea during ripening.

There was no tartaric acid detected in the berry exudates at any time during the season. Tartaric acid within the grape accumulates during the early stages in berry growth, then remains relatively constant during fruit ripening (Crippen and Morrison, 1986). In fully ripe grape berries, the concentration of tartaric acid is higher than that of malic acid (Crippen and Morrison, 1986), which we found in berry exudates throughout the season. The lack of tartaric acid in the exudates suggests that exudation is compound-specific, and not due to uncontrolled leakage of constituents from within the fruit. Differences in the accumulation patterns of malic acid, sugar, and phenolic compounds within the fruit and on the surface support this suggestion.

The sharp increase in the amount of sugar in the berry exudates 3 weeks after the start of ripening is in agreement with reports by Kosuge and Hewitt (1964) that both glucose and fructose increased on the surface of grapes as ripening progressed. Doneche (1986) correlated increases in surface sugars with the increase in the sugar content of the fruit. We similarly found a general correlation with internal sugar content, although the increase in exuded sugar began 3 weeks after the start of sugar accumulation in the fruit. The fruit reached $15 \%$ to $18 \%$ sugar before changes were evident in the exudates.

The promotive effect of the water-soluble berry exudates on B. cinerea mycelial growth may be at least partially due to the presence of sugars, which were also shown to stimulate germination of B. cinerea conidia (Blakeman, 1975; Coley-Smith et al., 1980; Harper et al., 1981). Doneche and Pucheu-Planté (1986) and Kosuge and Hewitt (1964) reported that the stimulation of Botrytis germination by grape exudates increased in the last month of ripening, which corresponds to the period in which we observed a large increase in sugar content of the exudates. Although it had been previously reported that grape exudates stimulate growth of B. cinerea (Doneche, 1986; Kosuge and Hewitt, 1964), both of the studies cited began sampling after the fruit had begun to ripen. We found that watersoluble exudates from grapes sampled at any time during the season promoted mycelial growth over controls grown in PDB only.

The presence of inhibitory substances in the ethanol and ether extracts after bloom is in agreement with Pezet and Pent (1984), who similarly reported inhibitory compounds on the surface of 'Gamay' grapes in the early stages of berry development. Phenols are one of several groups of compounds that were shown to inhibit the germination of $B$. cinerea conidia (Nyerges et al., 1975). We found a decrease in phenols per unit surface area over the growing season. The concentration of phenols within the grape berry also decreases over the season, but the total content per berry increases (Singleton and Esau, 1969). This pattern indicates that phenol biosynthesis continues during fruit development, but that the growth rate of the fruit is high relative to the rate of synthesis. We observed a decrease in the amount of phenolic exudate per berry as well as per unit surface area after veraison, which suggests that phenolic exudation slows or stops during ripening, even though phenols are still being synthesized in the fruit. The relatively high amount of phenolic compounds on the berry surface early in the growing season and the decrease during fruit development suggests that phenolic compounds may be involved in the change in susceptibility to Botrytis during ripening.

Viable conidia of $B$. cinerea were found on grape flowers and fruit throughout the growing season. However, grape berries are relatively resistant to Botrytis disease development until after the start of ripening (Hill et al., 1981). Data presented here are consistent with the suggestion that the changes in the composition of grape berry exudates over time may play a role in the early season resistance and late season susceptibility to $B$. cinerea infection.

\section{Literature Cited}

Barnett, H.L. 1987. Illustrated genera of imperfect fungi. Macmillan, New York.

Bergmeyer, H.U. 1974. Methods of enzymatic analysis. 2nd ed. Academic, New York.

Bessis, R. 1972a. Etude de l'évolution des caractéres morphologiques des cires cuticulaires au tours de la vie du fruit de la vigne. Compt. Rend. Acad. Sci. Paris 274:1911-1914.

Bessis, R. 1972b. Etude de l'évolution des stomates et des tissues péristomatiques du fruit de la vigne. Compt. Rend. Acad. Sci. Paris 274:2158-2161.

Bessis, R. 1977. Caractéres et développement des exsudats au tours de la maturation du raisin. Proc. Symp. IIF et OIV, Science et Technique Froid, Paris. 1977.

Blaich, R., U. Stein, and R. Wind. 1984. Perforationen in der cuticula 
von weinbeeren als morphologischer faktor der botrytisresistenz. Vitis $23: 242-256$.

Blakeman, J.P. 1975. Germination of Botrytis conidia in vitro in relation to nutrient conditions on leaf surfaces. Trans. Brit. Mycol. Soc. 65:239-247.

Brown, M.A. 1925. On the exosmosis of the nutrient substances from the host tissue in the infection drop. Ann. Bet. 36:101-119.

Coley-Smith, J. R., K. Verhoeff, and W. R. Jarvis (eds.). 1980. The biology of Botrytis. Academic, London.

Crippen, D. D. and J. C. Morrison. 1986. The effects of sun exposure on the compositional development of Cabernet Sauvignon berries. Amer. J. Enol. \& Viticult. 37:235-242.

Doneche, B. 1986. La nature des exsudats de raisins et leur rôle clans la germination des conidies de Botrytis cinerea. Agronomic 6:6773.

Doneche, B. and B. Pucheu-Planté. 1986. Influence de divers effecteurs sur le développement de Botrytis cinerea en milieu synthétique. Vitis 25:21-30.

Harper, A. M., R.N. Strange, and P. Langcake. 1981. Characterization of the nutrients required by Botrytis cinerea to infect broad bean leaves. Physiol. Plant Pathol. 19:153-167.

Hill, G., F. Stellwaag-Kittler, and E. Schlosser. 1981. Resistance of grapes in different developmental stages to Botrytis cinerea. Phytopathol. Z. 102:328-338.

Kosuge, T. and W.B. Hewitt. 1964. Exudates of grape berries and their effect on germination of conidia of Botrytis cinerea. Phytopathology 54: 167-172.

Labavitch, J. M., C.R. Heintz, H.L. Rae, and A.A. Kader. 1982 Physiological and compositional changes associated with maturation of 'Kerman' pistachio nuts. J. Amer. Soc. Hort, Sci. 107:688-692.

Langcake, P. 1981. Disease resistance of Vitis spp. and the production of the stress metabolizes resveratrol, e-viniferin, a-viniferin and pterostilbene. Physiol. Plant Pathol. 18:213-226.

Marois, J. J., J.K. Nelson, J.C. Morrison, L.S. Lile, and A.M. Bledsoe. 1986. The influence of berry contact within grape clusters on the development of Botrytis cinerea and epicuticular wax. Amer. J. Enol. \& Viticult. 37:293-296.

McClellan, W.D. and W.B. Hewitt. 1973. Early Botrytis rot of grapes: Time of infection and latency of Botrytis cinerea Pers. in Vilis vinifera L. Phytopathology 63:1151-1157.

Nyerges, P., E. Szabo, and E. Donko. 1975. The role of anthocyanin and phenol compounds in the resistance of grapes against Botrytis infection. Acts Phytopathol. 10:21-32.

Padgett, M. 1989. Changes in grape berry exudates during fruit development and their effect on germination of Botrytis cinerea conidia. MS Thesis, Univ. of California, Davis.

Pezet, R. and V. Pent. 1984. Botrytis cinerea: Activité antifongique dans les jeunes grappes de Vitis vinifera, varieté Gamay. Phytopathol. Z. 111:73-81.

Pucheu-Planté, B. and M. Mercier. 1983. Etude ultrastructurale de l'interrelation hôte-parasite entre le raisin et le champignon Botrytis cinerea example de la pourriture noble en Sauternais. Can. J. Bet. 61:1785-1797.

Rosenquist, J.K. and J.C. Morrison. 1988. The development of the cuticle andepicuticular wax of the grape berry. Vitis 27:63-70.

Sail, M. A., B. L. Teviotdale, and S. D. Savage. 1981. Bunch rots, p. 51-56. In: Grape pest management. Univ. Calif. Agr. Sci. Pub]., Berkeley, Calif.

Savage, S.D. and M.A. Sail. 1981. Radioimmunosorbent assay for Botrytis cinerea. Phytopathology 71:411-415.

Singleton, V.L. and J.A. Rossi. 1965. Calorimetry of total phenolics with phosphomolybdic and phosphotungstic acid reagents. Amer. J. Enol. \& Viticult. 16:144-158.

Singleton, V.L.and P. Esau. 1969. Phenolic substances in grapes and wines, and their significance. Adv. Food Res. Suppl. 1. Academic, New York.

Updegraff, D.M. 1969. Semimicro determination of cellulose in biological materials. Anal. Biochem. 32:420-424.

Vidal, M. and J. Blouin. 1978. Dosage colorimétrique rapide clans l'acid tartrique dans le mouts et les vins. Rev. Fr. Oenol. 70:3946. 